\title{
Pendeteksian Gangguan Radio pada Band UHF yang Terpantau di Kota Makassar
}

\author{
Irawati Razak \\ ${ }^{1}$ Teknik Elektro, Politeknik Negeri Ujung Pandang \\ a email: ira_razak@yahoo.com
}

\begin{abstract}
This research is proposed to monitor and detect radio signal disturbances which affect performance and quality of radio signal. The detected frequency spectrum is limited in range of $700 \mathrm{MHz}$ until $950 \mathrm{MHz}$. The location of research is in Makassar, which cooperate with Kantor Balai Monitor Frekuensi Radio Kelas II Makassar di Kabupaten Gowa, SulawesiSelatan. The detection of radio signal used VNA and SPA. Those differs performance of radio signal against source of disturbance, whether come from nature factor or human factor. The result of research is performance of radio signal that show effect of radio disturbance in frequency range of 800MHz until $950 \mathrm{MHz}$. Signal pattern which have good performance of radio signal showed a pattern of continuous radio signal that gain good signal quality, clearance voice and signal radius of $15 \mathrm{~km}$. While bad performance of radio signal show random signal radio (the disturbance is nature factor) and interference with illegal radio signal (disturbance is human factor).
\end{abstract}

Keywords: Radio, RFI, Frequency, Disturbance

Abstrak-Gangguan frekuensi oleh sinyal dari sumber transmisi frekuensi radio lainnya saat ini sudah semakin kerap terjadi khususnya di kota Makassar. Polusi frekuensi sudah semakin meningkat sejalan dengan semakin podatnya penggunaan spektrum frekuensi radio untuk berbagai keperluan. Penelitian ini bertujuan untuk mengamati dan mendeteksi gangguan sinyal radio yang mempengaruhi perfomansi/kualitas sinyal radio. Spektrum frekuensi yang akan dijadikan objek pengamatan dibatasi dalam rentang frekuensi $700 \mathrm{MHz}$ sampai $950 \mathrm{MHz}$. Lokasi pengamatan di kota Makassar dengan bekerjasama Kantor Balai Monitor Frekuensi Radio Kelas II Makassar di Kabupaten Gowa, Sulawesi Selatan.Pendeteksian sinyal radio menggunakan peralatan VNA (Vector Network Analyzer) dan SPA (Signal specrum Analyzer). Kedua peralatan tersebut membedakan perfomansi sinyal radio terhadap sumber gangguan, apakah gangguan terjadi berasal dari alam atau manusia. Hasil penelitian adalah pola sinyal yang menunjukkan perfomansi/kualitas sinyal radio akibat adanya gangguan radio dalam rentang frekuensi $800 \mathrm{MHz}$ hingga $950 \mathrm{MHz}$. Pendeteksian ini dapat dimanfaatkan oleh Balai Monitor Spektrum Frekuensi Radio Kelas II wilayah Makassar untuk memprediksi berat atau ringannya gangguan yang terjadi pada gelombang radio dalam beberapa tahun mendatang sehingga dapat meminimalkan terjadinya gangguan dan menangani gangguan dengan segera. Diharapkan hasil penelitian ini dapat menjadi naskah akademik bagi Kementerian Komunikasi dan Informatikan Republik Indonesia dalam membuat berbagai kebijakan dan aturan terkait dengan masalah penanggulangan Radio Frequency Interference (RFI) di Indonesia.

Kata Kunci: Radio, RFI, Frekunesi dan Gangguan

\section{Pendahuluan}

Gangguan gelombang/frekuensi radio merupakan gangguan akibat energi yang tidak dikehendaki yang disebabkan oleh satu atau kombinasi emisi-emisi, radiasi-radiasi atau induksi-induksi terhadap penerimaan dalam sistem komunikasi radio yang ditujukan dengan adanya suatu penurunan mutu, salah pengertian atau hilangnya informasi yang dapat diperoleh kembali bila energi yang tidak dikehendaki tersebut dihilangkan.

Gangguan disebabkan oleh berbagai faktor, diantaranya jarak antara pemancar dan penerima dimana terjadi multipath sehingga mempengaruhi kualitas penerimaan sinyal. Gangguan frekuensi radio dapat berupa interferensi, atenuasi, refleksi dan hal-hal yang menurunkan kualitas penerimaan sinyal [1]. Pemanfaatan spekrum frekuensi radio yang bebas gangguan berpotensi menghasilkan nilai tertinggi dari sumber daya spekrum frekuensi radio. Karakteristik gangguan frekuensi radio perlu diklasifikasikan agar dapat diprediksi sehingga meminimalkan gangguan yang terjadi dan penanganan gangguan dapat diatasi dengan segera.

Spekrum frekuensi radio merupakan sumber daya alam yang terbatas yang mempunyai nilai strategis dalam penyelenggaraaan telekomunikasi dan dikuasai oleh Negara, yang memerlukan perizinan dan pengawasan serta pengendalian sehingga tidak saling mengganggu. Dalam perizinan diatur daya pancar, luas 
jangkauan dan lebar pita. Gelombang radio adalah gelombang elektromagnetik yang dipancarkan melalui antena. Gelombang radio memiliki frekuensi yang berbeda-beda sehingga memerlukan penyetelan frekuensi tertentu yang sesuai dengan penerima radio untuk memperoleh sinyal yang dipancarkan. Frekuensi radio berkisar antara $3 \mathrm{KHz}$ hingga $300 \mathrm{GHz}$.

Spekrum frekuensi radio adalah susunan pita frekuensi radio yang mempunyai frekuensi yang lebih kecil dari $300 \mathrm{GHz}$ sebagai satuan getaran gelombang elektromagnetik yang merambat dan terdapat dalam dirgantara (ruang udara dan antariksa).

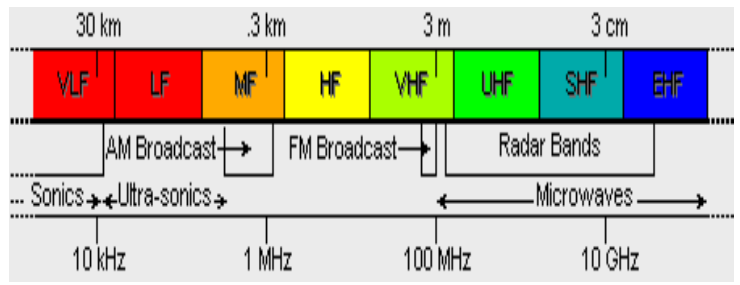

Gambar 1. Spekrum Frekuensi Radio

Keterangan:

-VLF = Very Low Frequency: $30-300 \mathrm{KHz}$

-LF = Low Frequency: 300-500 KHz

-MF = Medium Frequency: $500-1600 \mathrm{KHz}$

- HF = High Frequency: 3-30 MHz

-VHF = Very High Frequency : $30-300 \mathrm{MHz}$

-UHF = Ultra High Frequency: $300-3000 \mathrm{MHz}$

-SHF = Super High Frequency: $3-30 \mathrm{GHz}$

-EHF $=$ Extra High Frequency : $30 \mathrm{GHz}<\ldots$

-UV = Ultraviolet Light

Pengalokasian spekrum frekuensi radio di Indonesia mengacu kepada alokasi frekuensi radio internasional untuk wilayah 3 sesuai dengan peraturan radio yang ditetapkan oleh International Telecommunication Union (ITU) [2]. Penetapan jalur atau spekrum frekuensi radio yang menentukan kegunaaannya ini bertujuan untuk menghindari terjadinya gangguan dan untuk menetapkan protokol demi keserasian pemancar dan penerima.

Pada sistem telekomunikasi radio, yang dimaksud dengan kanal transmisi adalah medium ruang bebas baik udara maupun ruang hampa. Selama dalam perambatannya, gelombang radio akan mengalami [3]:

- Redaman (attenuation) dalam medium seperti pepohonan, gunung, gedung dan benda penghalang lainnya.

- Pemantulan (reflection) oleh permukaan bumi, gedung, gunung, pesawat terbang yang sedang melintas atau benda logam lainnya yang berada dijalur lintasan gelombang radio.

- Difraksi (difraction), yang terjadi ketika gelombang radio membentur penghalang tajam dan keras, seperti puncak gunung atau bendabenda lain seperti gedung bertingkat.

- Cacat (distortion) amplitudo, cacat frekuensi dan fasa.

- Gangguan frekuensi lain (interference).

Jika dimisalkan bahwa tidak terjadi pantulan oleh benda sekitar antena atau penyerapan energi diruang bebas, maka rapat daya akan seragam di setiap titik permukaan antena [4, 5]. Rapat daya dipermukaan antena penerima dinyatakan dengan persamaan:

Power density $=P_{T} / 4 \pi \mathrm{d}^{2}$

Jika antena penerima memiliki luas penampang efektif sebesar $A_{R}$, maka total daya yang diterima adalah :

$P_{R}=P_{T} \times A_{R} / 4 \pi \mathrm{d}^{2}$

Jika luas penampang efektif antena pemancar adalah $A_{T}$ maka penguatan antena pemancar dibandingkan terhadap radiator iostropis :

$g_{T}=4 \pi A_{T} / \lambda^{2}$

Dimana $\lambda$ adalah panjang gelombang dari sinyal emisi. Bila persamaan (2.3) didistribusikan kedalam (2.2), maka daya total yang diterima adalah pengaruh penerimaan daya oleh penguatan antena pemancar dan penerima serta kaitannya dengan frekuensi kerja $(c / \lambda)$ dan jarak antar pemancar dan penerima $(d)$ sebagai berikut :

$$
\begin{aligned}
P_{R} & =P_{T}\left(4 \pi A_{T} / \lambda^{2}\right)\left(4 \pi A_{R} / \lambda^{2}\right)(\lambda / 4 \pi \mathrm{d})^{2} \\
& =P_{T}\left(g_{T}\right)\left(g_{R}\right)(\lambda / 4 \pi \mathrm{d})^{2}
\end{aligned}
$$

Dimana $g_{R}=4 \pi A_{R} / \lambda^{2}$ penguatan antena penerima mengacu pada antena isotropis. Besaran jarak dan frekuensi pada persamaan (2.4a) dan (2.4b) disebut rugi-rugi ruang bebas (free-space loss) antara dua sumber isotropis. Free space loss (FSL) dalam satuan disebut decibel.

$\mathrm{FSL}_{\mathrm{dB}}=32.45+20 \log D_{\mathrm{km}}+20 \log F_{\mathrm{MHz}}$

Rumusan FSL sangat berguna untuk menghitung jaringan point-to-point dengan asumsi bahwa tidak ada penghalang dan cuaca bersih. Aturan ITU-R dalam P.525-2 memberikan rumus untuk menghitung kuat medan listrik untuk jaringan point-to-point sebagai berikut :

$$
E=\sqrt{\frac{30 p}{D}}
$$


Dimana $E$ adalah squre mean root (nilai rata-rata) dari kuat medan (field strength) dalam satuan volt/meter, dan $p$ adalah daya yang diradiasikan secara isotropis (EIRP $=$ Effective Isotropic Radiated Power $)$ dalam satuan watt, dan $D$ adalah jarak antara pemancar dan titik pengukuran dalam satuan meter.

\section{Metode Penelitian}

Gambar 2 menunjukkan prosedur kerja penelitian. Penelitian difokuskan pada band UHF (Ultra High Frequency) dalam range frekuensi $700-950 \mathrm{MHz}$. Pengukuran frekuensi menggunakan VNA (Vector Network Analyzer) dan SPA (Signal Specrum Analyzer). Metode pengukuran adalah membandingkan hasil pengukuran data yang bebas dari gangguan radio terhadap pengukuran data yang mengalami gangguan radio. Dari data pengukuran dianalisis bentuk sinyal yang berbeda terhadap jenis gangguan radio.

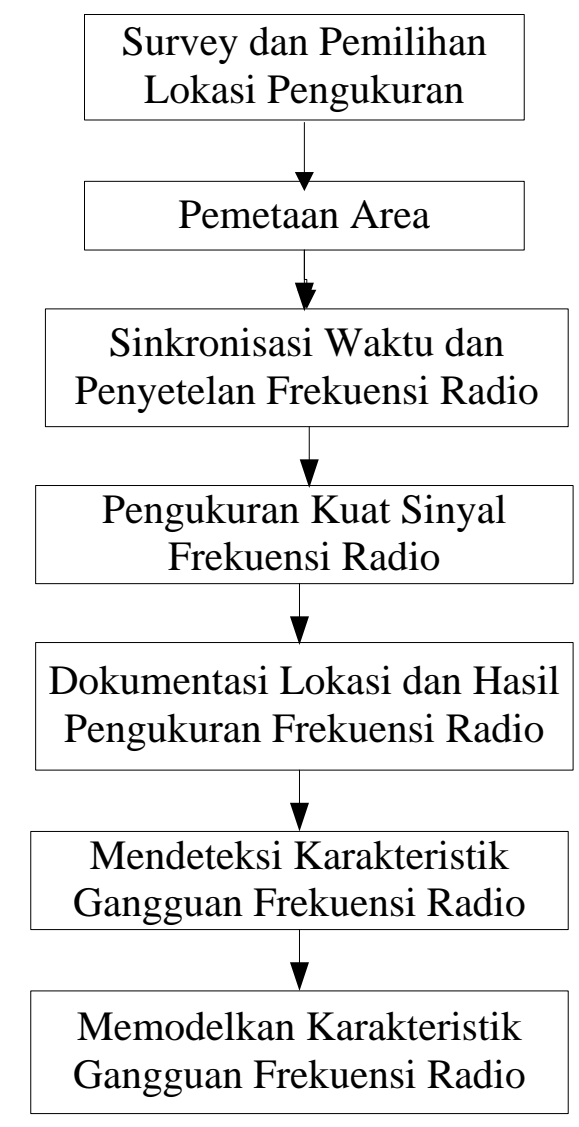

Gambar 2. Prosedur pelaksanaan penelitian

Pengukuran kuat sinyal tiap penerima radio dilakukan di sepanjang titik lokasi penerima radio pengguna frekuensi legal yang berada dalam wilayah Kota Makassar.

Pengolahan hasil dokumentasi dan pengukuran dilakukan di laboratorium Transmisi Sinyal Program Studi Teknik Telekomunikasi Politeknik Negeri Ujung Pandang. Desain pemodelan dilakukan di laboratorium High Frequency Program Studi Tekni Telekomunikasi Politeknik Negeri Ujung Pandang.

\section{Hasil dan Pembahasan}

Data penelitian adalah hasil pemantauan sinyal radio seluler pada frekuensi 800 hingga $950 \mathrm{MHz}$. Gambar 3 dan 4 menunjukkan performansi sinyal yang tidak mengalami gangguan radio.

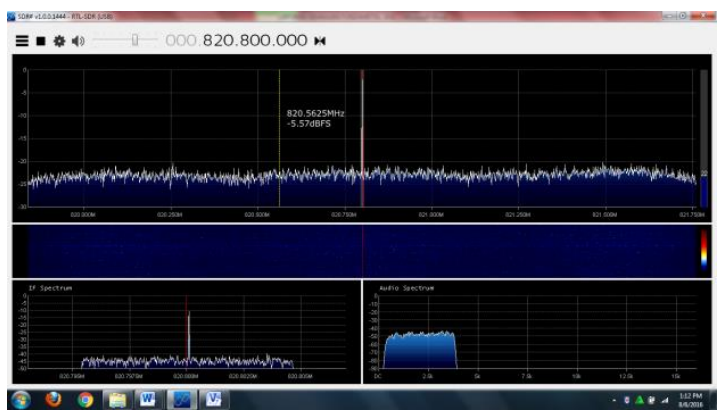

Gambar 3. Performansi Sinyal Yang Bebas Dari Ganggguan Radio Pada Frekuensi $820 \mathrm{MHz}$

Garis warna biru menunjukkan sinyal yang bersih dari gangguan radio. Performansi sinyal radio seluler dapat mencapai jangkauan hingga $15 \mathrm{~km}$. Kualitas komunikasi antar pengguna seluler menghasilkan capaian sinyal yang baik, suara yang jernih dan jangkauan sinyal yang jauh beradius $15 \mathrm{~km}$.

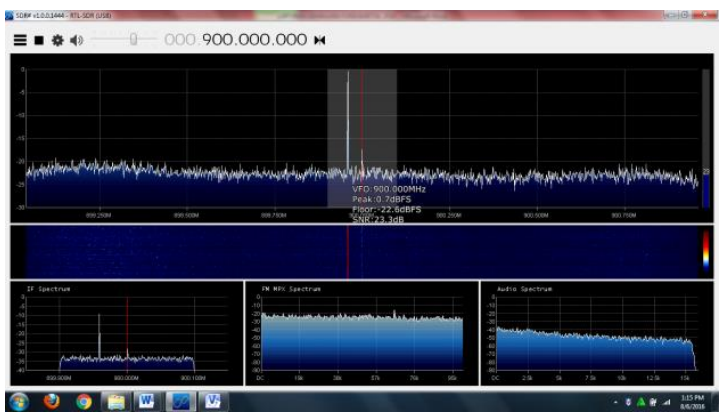

Gambar 4. Performansi Sinyal Yang Bebas Dari Ganggguan Radio Pada Frekuensi 900 MHz

Gambar 5 dan 6 menunjukkan performansi sinyal yang buruk akibat adanya gangguan radio. Gangguan radio dapat berasal dari manusia atau alam. Dari manusia 
yaitu penyalahgunaan frekuensi sehingga mengganggu frekuensi radio BTS yang legal. Sedangkan dari alam yaitu anomali cuaca yang tidak menentu dalam serahun.

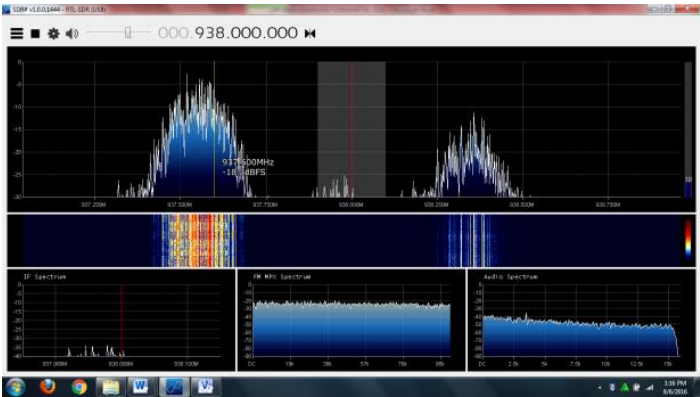

Gambar 5. Performansi Sinyal Yang Buruk Akibat Ganggguan Radio Pada Frekuensi 938 MHz

Pada gambar 5, garis vertikal warna merah dan jingga menunjukkan adanya interferensi frekuensi dari perangkat pemancar lain yang tidak berlisensi. Perangkat pemancar tersebut berada di sekitar BTS (Base Transceiver Station). Jenis gangguan radio ini berasal dari manusia yakni penyalahgunaan kanal frekuensi.

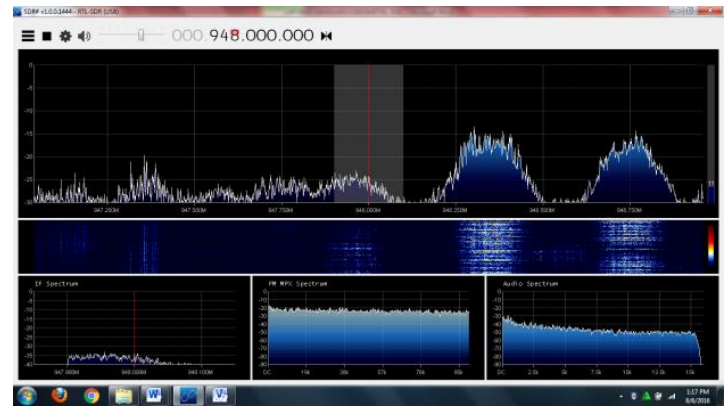

Gambar 6. Performansi Sinyal Yang Buruk Akibat Ganggguan Radio Pada Frekuensi 948 MHz

Pada gambar 6, performansi sinyal meningkat secara acak yang menunjukkan terdeteksinya noise/derau pada layar SPA. Jenis gangguan radio ini berasal dari alam yakni anomali cuaca.

Berikut adalah hasil perhitungan daya terima dan FSL dari tampilan gambar 3 hingga gambar 6 yang merujuk pada persamaan 2.4 dan 2.5. Nilai daya pancar diketahui adalah 2,5 watt, gain pemancar adalah 17,4 dB dan gain SPA adalah $1 \mathrm{~dB}$.
Tabel 1. Nilai Pr dan FSL

\begin{tabular}{ccc}
\hline $\begin{array}{c}\text { Frekuensi } \\
(\mathbf{M H z})\end{array}$ & Pr $(\mathbf{d B m})$ & FSL $(\mathbf{d B})$ \\
\hline 820 & 17,1 & 90,732 \\
900 & 17,92 & 91,534 \\
938 & 18,26 & 91,894 \\
948 & 18,36 & 91,986 \\
\hline
\end{tabular}

Tabel 1 menunjukkan bahwa semakin tinggi frekuensi, perolehan daya terima akan semakin besar. Nilai rugi-rugi propagasi ruang bebas (FSL) akan meningkat sesuai dengan meningkatnya nilai frekuensi pancar BTS.

\section{Kesimpulan}

Berdasarkan analisis diperoleh kesimpulan sebagai berikut :

1. Pendeteksian dilakukan dengan menggunakan sebuah alat ukur yang menunjukkan performasi sinyal radio seluler.

2. Pendeteksian gangguan radio dapat diakibatkan oleh penyalahgunaan kanal frekuensi yang tidak berlisensi (faktor manusia) dan anomali cuaca (faktor alam).

3. Dampak dari adanya gangguan radio adalah ketidakjerniahan suara, komunikasi antar pengguna yang sering putus, jangkauan sinyal radio yang pendek yakni kurang dari radius $15 \mathrm{~km}$.

\section{Ucapan Terima Kasih}

Ucapan terima kasih ditujukan kepada Kantor Balai Monitor Frekuensi Radio Kelas II Makassar di Kabupaten Gowa, Sulawesi Selatan.

\section{Daftar Pustaka}

[1] Freeman, Roger.L.2007. Radio System Design for telecommunications. $3^{\text {rd }} E d$. IEEE Inc, New York, Printed by John Wiley \& Sons. USA.

[2] Recommendation ITU-R P.370-7. 1995. VHF and UHFPropagation Curves for the Frequency Range From 30 $\mathrm{MHz}$ to $1000 \mathrm{MHz}$

[3] Rappaport, Theodore S. 2002. Wireless Communications. New York: Pearson Education International

[4] Sizun,H. 2005. Radio Wave Propagation For Telecommunication Applications. Springer-Verlag Heidelberg - Germany.

[5] Yessi Arnaz Ferari (Juni, 2012), Manajemen Telekomunikasi, Analisis pemanfaatan spekrum frekuensi radio pada pita UHF (Ultra High Frequency). 